\title{
O CONCEITO DE ÉTICA PARA MARX E ENGELS
}

Maria Cristina Longo Cardoso Dias ${ }^{1}$

Resumo: O presente trabalho visa a explicitar o conceito de ética para Marx e Engels. O artigo propõe a compreensão da ética de Marx e Engels como subdividida em dois planos que se comunicam. O primeiro plano da ética seria derivado das relações dominantes de produção do capitalismo, como relações de exploração. Esse plano da ética revelaria valores indesejáveis como heterônima, desrespeito, exploração, relações de mando e hierarquia, egoísmo, competição, alienação, embrutecimento e coisificação das pessoas. Tal plano ético é objeto de crítica dos autores. O segundo plano da ética seria derivado da luta de classes que se coloca contra o modo de produção capitalista e seria composto de valores desejáveis como a não exploração, relações de igualdade entre as pessoas, altruísmo, autonomia, respeito, consciência, democracia e consideração entre os humanos.

Palavras-chave: Marx, Engels, Ética, Moral.

Abstract: Present paper aims to explain the concept of ethics to Marx and Engels. The article proposescomprehension of Marx's and Engels' ethics divided in two plans which communicate themselves. First ethical plan would be derived from dominant relations of production in capitalism, such as exploitation. This ethical plan would reveal undesirable values like heteronomy, disrespect, exploitation, authority relations and hierarchy, egoism, competition, alienation, brutalization, reduction of human beings to things. This ethical plan is criticized by authors. Second ethical plan would be derived from class conflict which fight against capitalist mode of production and would be composed by desirable values such as no exploitation, relations of equality among people, altruism, autonomy, respect, conscience, democracy and consideration among human beings.

Key-Words: Marx, Engels, Ethics, Morality.

${ }^{1}$ Possui graduação em economia e filosofia pela USP, é mestre e doutora em filosofia por esta mesma instituição. É professora adjunta do departamento de filosofia da UFRN. 
O presente trabalho visa a elucidar de que forma pode-se compreender o tema da ética e da moral no sistema de pensamento de Marx e Engels. Faz-se uma distinção entre os termos ética e moral nesse trabalho. Entende-se o termo ética como uma reflexão teórica sobre os valores morais que as pessoas sustentam na realidade. Contudo, a ética marxiana não é composta de conceitos abstratos a serem descobertos por pensadores, mas é uma reflexão sobre valores morais sustentados por pessoas reais.

Embora Marx e Engels não tenham escrito nenhum livro ou ensaio específico sobre ética, podem-se traçar dois planos do pensamento ético no sistema dos autores: o primeiro plano seria derivado de uma crítica aos valores morais vigentes, pois estes espelhariam e reforçariam relações de exploração. O segundo plano da ética, na teoria de Marx e Engels, estaria em construção e seria procedente da ação transformadora da sociedade a partir da luta de classes existente.

Para traçar tais planos da ética na teoria de Marx e Engels, torna-se necessário compreender alguns elementos de seus sistemas de pensamento.

Em primeiro lugar, a teoria de Marx, conforme afirmação do próprio autor, não trata de conceitos meramente abstratos descobertos por algum reformador do mundo ou aborda generalizações que não dizem respeito à realidade. De acordo com Marx, seus escritos consistem em uma análise da realidade da organização social e versam sobre as relações sociais reais inseridas em um contexto que existe.

Segundo uma verificação histórica efetuada por Marx e Engels, a partir de seu método materialista histórico dialético, é possível depreender que todas as sociedades em todos os tempos organizaram-se para a produção. Sobre isto cito Engels (1880, p.49):

A concepção materialista da história parte da tese de que a produção, e com ela a troca dos produtos, é a base de toda a ordem social; de que em todas as sociedades que desfilam pela história, a distribuição dos produtos, e juntamente com ela a divisão social dos homens em classes ou camadas, é determinada pelo que a sociedade produz e como produz e pelo modo de trocar os seus produtos.

Ou seja, os homens, em todas as sociedades passadas e na sociedade atual estabelecem determinadas relações voltadas para a produção de bens necessários à sua

\begin{tabular}{|l|l|l|l|l|}
\hline Q Ronista Dialectus & Ano 3 & n. 8 & Janeiro - Agosto 2016 & p. 134-145 \\
\hline
\end{tabular}


sobrevivência ${ }^{2}$. Os valores que emanam da forma dominante de relações voltadas à produção, bem como a maneira como luta-se contra essas relações dominantes constituem os valores morais de uma época.

Conforme relata Engels, em seu livro A origem da família, da propriedade privada e do estado, as sociedades primitivas, por não possuírem propriedade privada ou classes sociais, não possuíam Estado $^{3}$ e os valores morais que seus membros sustentavam, como solidariedade, fraternidade, autonomia, não exploração e coletivismo, correspondiam às relações de produção daquela época, que ainda não eram baseadas em relações de classes e de dominação.

É a partir da análise da realidade, do exame de como as sociedades organizam-se para a produção que se torna possível entender a moral vigente, bem como formular uma proposta de transformação social que beneficie o surgimento de outro tipo de moral. A passagem abaixo, exposta por Vázquez, demonstra como só é possível compreender o indivíduo inserido no contexto das relações sociais que trava.

A tese de Marx nos mostra, em primeiro lugar, que não é no indivíduo que podemos encontrar a essência humana, mas sim nas relações sociais, das quais ele mesmo é um produto. $\mathrm{O}$ indivíduo à margem das relações é uma abstração, e a essência como atributo individual é tão abstrata quanto ele. Não existe a essência do homem como atributo comum dos indivíduos, simplesmente porque o indivíduo isolado não existe realmente. A essência humana universal e a natureza humana dos indivíduos só podem ser desvendadas no conjunto de relações sociais que produzem tanto a natureza do homem social como a de indivíduos. (Vázquez, 1977, p.422).

\footnotetext{
${ }^{2}$ Marx e Engels, 2007, p. 33: "O primeiro ato histórico é, pois, a produção dos meios para a satisfação dessas necessidades, a produção da própria vida material, e este é, sem dúvida, um ato histórico, uma condição fundamental de toda a história que ainda hoje, assim como há milênios, tem de ser cumprida diariamente, a cada hora, simplesmente para manter os homens vivos".

${ }^{3}$ Engels, 1984, p.195: "Portanto, o Estado não tem existido eternamente. Houve sociedades que se organizaram sem ele, não tiveram a menor noção do Estado ou de seu poder. Ao chegar a certa fase de desenvolvimento econômico, que estava necessariamente ligada à divisão da sociedade em classes, essa divisão tornou o Estado uma necessidade".
}

\begin{tabular}{|l|l|l|l|l|}
\hline Q Rovista Qialectus & Ano 3 & n. 8 & Janeiro - Agosto 2016 & p. 134-145 \\
\hline
\end{tabular}


O capitalismo, assim descrito por Marx, é o modo de produção atual que possui apropriação privada do produto embora sua produção ocorra coletivamente. Nesse modo de produção, os possuidores de capital são os donos dos meios de produção que empregam trabalhadores a fim de produzir mercadorias e acumular capital. Os trabalhadores, por sua vez, não possuem nada além de sua força de trabalho para vender no mercado de trabalho.

Embora os trabalhadores sejam os responsáveis pela produção de mercadorias, embora sejam eles que agreguem valor às mercadorias através do trabalho, eles não se apropriam do que produzem, mas apenas de um salário muitas vezes insuficiente para garantir sua subsistência. Em outras palavras, o valor das mercadorias é determinado pelo tempo de trabalho socialmente necessário para produzi-las, é dado pelo tempo de trabalho social incorporado à mercadoria, embora a quase totalidade de seu valor seja apropriada pelos donos de capital. É precisamente no trabalho não pago ao trabalhador que consiste a exploração do capitalismo.

Exploração essa que é inerente à existência do capitalismo. Enquanto houver capitalismo haverá exploração, pois a acumulação de capital ocorre devido à extração do mais-valor. Do elemento central ou estrutural da sociedade, a saber: as relações sociais que surgem a partir de determinada organização social de produção, ergue-se uma superestrutura, constituindo elementos jurídicos, morais, políticos e religiosos. Em outras palavras, o autor afirma que a moral é derivada das relações necessárias que são estabelecidas na produção.

Na produção social da própria vida, os homens contraem relações determinadas, necessárias e independentes de sua vontade, relações de produção estas que correspondem a uma etapa determinada do desenvolvimento das forças produtivas materiais. A totalidade destas relações de produção forma a estrutura econômica da sociedade, a base real sobre a qual se levanta uma superestrutura jurídica e política, e à qual correspondem formas determinadas de consciência. $\mathrm{O}$ modo de produção da vida material condiciona o processo em geral de vida social, político e espiritual. (Marx, 1974, pp.129-130).

\begin{tabular}{|l|l|l|l|l|}
\hline Q Rovista Dialectus & Ano 3 & n. 8 & Janeiro - Agosto 2016 & p. 134-145 \\
\hline
\end{tabular}


Desta forma, o primeiro plano da ética estaria relacionado a uma superestrutura que se ergue do aspecto dominante da realidade da organização social atual e seria objeto de crítica do autor, enquanto que o segundo plano da ética pode ser relacionado à luta pelo surgimento de uma nova sociedade, a partir de sua transformação.

O primeiro plano da ética e da moral está ligado ao modo estruturante da produção vigente e sustenta os valores necessários ao funcionamento desse sistema. De acordo com Marx, a moral dominante, a política dominante e a religião dominante, no capitalismo, são meros preconceitos burgueses ${ }^{4}$, pois fazem parte de uma superestrutura que serve ao modo de produção atual. Segundo o autor, na passagem do feudalismo para o capitalismo, todos os valores cavalheirescos, laços de confiança são substituídos pelo laço do frio interesse ${ }^{5}$. A liberdade e a igualdade consolidam-se como valores essenciais ao capitalismo, embora signifiquem liberdade de comércio e igualdade entre possuidores de mercadorias.

As virtudes cardeais desse sistema, conforme afirma Marx, são a parcimônia e a avareza $^{6}$ que os indivíduos cultivam quanto mais desejam o capital. O Estado ${ }^{7}$ ergue-se, principalmente, para garantir os direitos fundamentais dos possuidores de capital como o direito à propriedade, conforme frisa o autor no Manifesto Comunista $(2010$, p.42) "o executivo no Estado moderno não é senão um comitê para gerir os negócios comuns de

\footnotetext{
${ }^{4}$ Marx, a2010, p.49: "As leis, a moral, a religião, são para ele meros preconceitos burgueses, atrás dos quais se ocultam outros tantos interesses burgueses".

${ }^{5}$ Marx, 2010a, p. 40: "Onde quer que tenha conquistado poder, a burguesia destruiu todas as relações feudais patriarcais, idílicas. Dilacerou sem piedade todos os complexos e variados laços que uniam o homem feudal a seus superiores naturais para não deixar subsistir, entre homem e homem, outro vínculo senão o frio interesse, as duras exigências do 'pagamento em dinheiro'. Afogou os sagrados frêmitos do êxtase religioso, do entusiasmo cavalheiresco, do sentimento pequeno-burguês nas águas geladas do cálculo egoísta. Fez da dignidade pessoal um simples valor de troca e, no lugar das inúmeras liberdades tão duramente conquistadas, implantou a única e implacável liberdade decomércio. Numa palavra, em lugar da exploração que as ilusões políticas e religiosas mascaravam, implantou uma exploração aberta, despudorada, direta e brutal".

${ }^{6}$ Marx, 2013, p. 207: "Quanto mais ele (o capitalista) produz, tanto mais ele pode vender. Trabalho árduo, parcimônia e a avareza constituem, assim, suas virtudes cardeais e vender muito e comprar pouco sãoa suma de sua economia política".

${ }^{7}$ Pensando o sistema de Marx e Engels a partir de seu método dialético pode-se concluir que todas as esferas da vida e das instituições apresentam as contradições presentes nessa forma de organizar a sociedade. Dessa forma, o Estado embora sirva, predominantemente, ao capital também expressa, em menor medida, as conquistas derivadas das lutas de classe como as garantias trabalhistas, por exemplo.
}

\begin{tabular}{|l|l|l|l|l|}
\hline Rovita Dialectus & Ano 3 & n. 8 & Janeiro - Agosto 2016 & p. 134-145 \\
\hline
\end{tabular}


toda classe burguesa". As leis jurídicas, portanto, são principalmente construídas com o objetivo de proteger os direitos da classe dominante (dos detentores de capital), assim como os valores morais, a religião e outros elementos da superestrutura servem, fundamentalmente, para sustentar o modo de produção dominante.

As subjetividades e os modos de ser que surgem das relações de produção dominantes no sistema capitalista são bastante marcados. $\mathrm{O}$ capitalista aparece como o personagem cujo objetivo de vida principal é a acumulação de capital, a valorização do valor. Entretanto, o capitalista gera tanto mais-valor quanto mais ele explora a força de trabalho, seja extraindo mais-valor absoluto através do aumento da jornada de trabalho, seja ampliando o mais valor-relativo, diminuindo o tempo de trabalho necessário em que o trabalhador se paga relativamente ao tempo de trabalho excedente apropriado pelos donos do capital, através do incremento tecnológico. Em outras palavras, o capitalista lucra tanto mais, quanto mais ele gasta vidas humanas.

De outra parte, a subjetividade dos trabalhadores é constituída em um ambiente de coação, hierarquia, mando, exploração, opressão, heteronomia, embrutecimento, mal-estar, alienação, coisificação e estranhamento. O trabalhador vê-se obrigado a vender sua força de trabalho para se apropriar de um salário muitas vezes insuficiente para garantir sua subsistência e sempre menor do que o que ele produz. A força de trabalho é, dentro do modo de produção capitalista, tratada como coisa, visto ser mais uma mercadoria a ser gasta como tantas outras. Em outras palavras, quanto mais a mercadoria força de trabalho é gasta, mais valor ela gera, valor que, contudo, é usurpado dela pelo capitalista. Além de coagido e explorado, no sentido de que o trabalhador apropria-se pouco do que produz, ele precisa responder a relações de hierarquia e mando, dado que, em uma relação jurídica, vende seu tempo aos donos dos meios de produção que se sentem no direito de usá-lo como bem entenderem durante esse período $^{8}$. Ademais, os trabalhadores compreendem pouco o processo de produção, devido ao aprofundamento da divisão do trabalho e veem-se embrutecidos pela

${ }^{8}$ Hoje em dia, em alguns países, há leis que determinam como os capitalistas podem gastar a mercadoria força de trabalho.

\begin{tabular}{|c|c|c|c|}
\hline Rovista Dialectus & Ano 3 & n. 8 & Janeiro - Agosto 2016 \\
\hline
\end{tabular}


quantidade de trabalho que precisam despender sem que sua criatividade e prazer sejam estimulados em tais ambientes.

$\mathrm{O}$ antigo possuidor de dinheiro se apresenta agora como capitalista, e o possuidor de força de trabalho, como seu trabalhador. O primeiro, com um ar de importância, confiante e ávido por negócios; o segundo, tímido e hesitante, como alguém que trouxe sua própria pele ao mercado e, agora, não tem mais nada a esperar além da...despela. (Marx, 2013, p.223).

Embora seja possível depreender esse primeiro plano da ética como produtora de valores morais e subjetividades vinculadas às relações sociais de exploração, torna-se possível vislumbrar um segundo plano da ética que poderia ser pensado a partir da luta pela solução das contradições vigentes.

Em outras palavras, pode-se dizer que é possível cogitar uma nova ética com valores predominantes como o coletivismo, não exploração, solidariedade, liberdade, altruísmo, respeito e autonomia dos sujeitos, a partir da luta pela superação das atuais contradições, derivada da luta de classes existente no modo de produção capitalista.

Em outros termos, pode-se dizer que o conflito entre as duas classes centrais, a saber: o conflito entre os possuidores de capital e os não possuidores levaria à ação transformadora por parte daqueles que são oprimidos, ação esta cujo objetivo final seria a abolição da propriedade privada, tomada do poder político e coletivização dos meios de produção.

A partir das relações sociais que existem e de suas contradições também reais seria possível observar a transformação social para uma forma de produzir que além de ser coletiva, gere também a apropriação coletiva do produto. Sem fortes desigualdades sociais, com a coletivização da apropriação do produto, sem o estímulo do capitalismo à busca desenfreada por capital, em uma sociedade em que todos pudessem opinar de forma não hierárquica, o resultado seria a solidariedade, democracia ${ }^{9}$, não opressão,

\footnotetext{
${ }^{9}$ Marx, a2010, p.56: "Vimos antes que a primeira fase da revolução operária é a elevação do proletariado à classe dominante, a conquista da democracia".
}

\begin{tabular}{|c|c|c|c|c|}
\hline Rovista Dialectus & Ano 3 & n. 8 & Janeiro - Agosto 2016 & p. $134-145$ \\
\hline
\end{tabular}


respeito e autonomia dos sujeitos - valores que comporiam o segundo plano da ética de Marx, ligados à transformação social.

Contudo, esses valores contrários aos dominantes já são verificados na própria sociedade capitalista que emanam, precisamente, da luta contra essa forma de organizar a produção. $\mathrm{O}$ método dialético ${ }^{10}$ de Marx é um método que permite o convívio desses valores contraditórios, porque reconhece que a própria forma de organizar a produção e a sociedade é contraditória, pelo fato de que embora a produção seja social e coletiva sua apropriação é privada e, portanto, baseada na exploração, na extração de mais-valor. Esse fato gera resistência pelos trabalhadores que culmina no próprio processo de luta pela superação do modo de produção dominante, terminando por originar, durante a própria luta, valores contrários aos valores dominantes.

Em outras palavras, os valores éticos dominantes como a ganância, o egoísmo, a competição, o individualismo, a avareza, a cobiça e a exploração, responsáveis por sustentar o sistema dominante, somente serão modificados e convertidos em solidariedade, fraternidade, respeito, justiça, autonomia, democracia e confiança entre os humanos, com a luta pela transformação das bases materiais da sociedade. Uma vez que é a partir da luta pela transformação da forma de produção e apropriação do produto que se pode modificar as relações que os homens travam necessariamente em suas vidas. Com a mudança na forma de apropriação do produto, caso o produto passasse a ser apropriado coletivamente, não haveria propriedade privada do capital, assalariamento, nem tão pouco exploração, fatos que desestimulariam a corrida desenfreada pela busca de capital, a ganância, a competição, a avareza, o egoísmo, e outros valores nefastos gerados pelo atual modo de produção.

Contudo, esses valores contraditórios aos valores dominantes, derivados de lutas coletivas e individuais contra o modo de produção capitalista coexistem, muitas vezes com os próprios valores predominantes. Em outros termos, em última instância, uma

\footnotetext{
${ }^{10} \mathrm{O}$ método dialético de Marx e Engels permite a compreensão do todo social como composto de inúmeras contradições, sendo assim, não haveria porque imaginar que a ética marxiana não seria composta de contradições, quando a estrutura social é, da mesma forma, contraditória.
}

\begin{tabular}{|l|l|l|l|l|}
\hline Q Rovista Qialectus & Ano 3 & n. 8 & Janeiro - Agosto 2016 & p. 134-145 \\
\hline
\end{tabular}


mesma pessoa pode apresentar valores contraditórios, como individualismo e solidariedade, dependendo da situação, pois esses valores contraditórios emanam das próprias construções sociais contraditórias. Por exemplo, um trabalhador pode amenizar o embrutecimento e alienação que muitas vezes compõem sua subjetividade lutando por melhores condições de vida, adquirindo consciência de sua situação de classe. Um capitalista pode ter como objetivo principal de vida a acumulação de capital, e, portanto, explorar e coisificar os trabalhadores, mas durante o processo de exploração pode sensibilizar-se com o que percebe e passar a se colocar no ponto de vista do trabalhador, como Robert Owen o fez (embora tal atitude não seja muito comum).

Ou seja, a luta por melhores condições de vida no capitalismo geraria, já nesse próprio modo de produção, valores morais contrários aos dominantes. Esses valores contrários aos dominantes seriam consolidados com a completa transformação da sociedade a partir da tomada do poder político e coletivização dos meios de produção pelos trabalhadores. Conforme demonstra a passagem abaixo, a natureza humana pode ser completamente modificada dependendo da estrutura social.

“o homem não é por natureza, nem egoísta nem altruísta. Ele se torna, por sua própria atividade, aquilo que é num determinado momento. E assim, se essa atividade for modificada, a natureza humana hoje egoísta se modificará, de maneira correspondente”. (Mészáros, 2006, p.137).

Em uma sociedade com apropriação coletiva da produção, em que todos pudessem opinar livremente sobre seus trabalhos, em que não houvesse hierarquia ou mando, em que não houvesse exploração, ou o constante risco da perda do emprego e, portanto, da renda, as relações necessárias seriam modificadas de forma a possibilitar o estímulo da autonomia dos sujeitos, exercício mais pleno de sua racionalidade, altruísmo, democracia, criatividade, solidariedade, liberdade e respeito pelos outros.

\begin{tabular}{|c|c|c|c|}
\hline Rovista Dialectus & Ano 3 & n. 8 & Janeiro - Agosto 2016 \\
\hline
\end{tabular}


Esse segundo plano da ética, contudo, conforme mencionou-se, não é constituído como um plano ideal a ser forçado na realidade, como querem muitos filósofos ${ }^{11}$, mas representa antes, uma possibilidade real de mudança da moral que só pode ser conquistada com a luta pela transformação das atuais condições de produção vigentes, a partir da ação humana.

Em outros termos, o segundo plano da ética na teoria de Marx, que afirmaria novos valores morais como a não exploração, solidariedade, autonomia dos sujeitos, altruísmo, liberdade, democracia, e respeito pelos outros também é derivado das relações que existem, contudo não é proveniente das relações dominantes, mas procede da ação transformadora social que ocorre através da luta de classes.

Assim, pode-se concluir que, para Marx e Engels, uma nova ética composta de pessoas que sustentem novos valores morais só pode ser conquistada a partir da luta pela transformação do modo de produção e apropriação do produto vigente.

\footnotetext{
${ }^{11}$ A crítica que Marx faz a muitos filósofos, especialmente em A Ideologia Alemãa, refere-se ao fato de que os mesmos partem de abstrações distantes da realidade, para então tentar implementá-las nas sociedades vigentes, quando deveriam fazer o movimento contrário, qual seja: partir da análise do real, do que existe para então tentar propor alguma mudança social.
}

\begin{tabular}{|c|c|c|c|}
\hline Rovista Dialectus & Ano 3 & n. 8 & Janeiro - Agosto 2016 \\
\hline
\end{tabular}




\section{Referências bibliográficas:}

ENGELS F. A origem da família, da propriedade privada e do Estado. Rio de Janeiro: Civilização Brasileira, 1984.

Do Socialismo utópico ao socialismo científico (1880). São Paulo:

EditoraMoraes, s/d.

. Anti-dühring. Rio de Janeiro: Paz e Terra, 1990.

FAUSTOR. Marx: Lógica e Política. São Paulo: editora 34, 2002.

HARVEY D. A companion to Marx's Capital.Londres: Verso, 2010. . The enigma of the capital and the crises of capitalism.Londres: profile books, 2010 .

LABRIOLA A. Em memória do Manifesto Comunista. São Paulo: Boitempo Editorial,2010.

LASKI, H. J. O Manifesto Comunista de Marx e Engels. São Paulo:Boitempo Editorial,2010.

LEFEBVRE, H. Para Compreender o Pensamento de Karl Marx. São Paulo: Martins Fontes, 1981.

LUKÁCS, G. Ontologia do Ser Social: os princípios ontológicos fundamentais de Marx. São Paulo: Ciências Humanas, 1979.

MARX K. e ENGELS F. A ideologia alemã. São Paulo:Boitempo Editorial, 2007. Manifesto comunista. São Paulo: Boitempo Editorial, a2010.

MARX K. O capital. São Paulo:Boitempo Editorial, 2013. . Manuscritos econômico-filosóficos. São Paulo: Boitempo Editorial, b2010.

\begin{tabular}{|c|c|c|c|}
\hline Rovista Dialectus & Ano 3 & n. 8 & Janeiro - Agosto 2016 \\
\hline
\end{tabular}


. O 18 de Brumário de Luís Bonaparte. São Paulo: Boitempo Editorial, 2011.

. Para a crítica da economia política. São Paulo: Abril Cultural, 1974.

MÉSZÁROS I. A teoria da alienação em Marx. São Paulo: Boitempo Editorial, 2006.

VÁZQUEZ, A. S. Ética e marxismo. Capítulode livro. Buenos Aires: CLACSO, Consejo Latinoamericano de Ciencias Sociales,

2007.Diponívelem:http://biblioteca.clacso.edu.ar/clacso/formacion-

virtual/20100715081236/cap12.pdf

.Filosofia da praxis. Rio de Janeiro: Paz e Terra, 1977.

. Ética. Rio de Janeiro: Civilização brasileira, 2010. 